\title{
Comparisons of Sentence Recognition Scores and Preferences according to Compression Types in a Multi-Channel Hearing Aid
}

\author{
Suyeon Shin ${ }^{1,2}$, Kyoungwon Lee ${ }^{2}$ \\ ${ }^{1}$ SSY Aural Rehabilitation Center, Daejeon, Korea \\ ${ }^{2}$ Department of Audiology, Hallym University of Graduate Studies, Seoul, Korea \\ 다채널보청기의 압축 방식에 따른 문장인지도와 선호도의 비교 \\ 신 수 연,2.이 경 원 \\ 신수연보청기청능재활센터', 한림국제대학원대학교 청각학과 ${ }^{2}$
}

\begin{abstract}
Purpose: The aims of this study were to investigate the sentence recognition score (SRS), clarity of speech sounds, perception of changes in the background noise and differences in the overall preference according to the compression types in a multi-channel hearing aid. Methods: 19 subjects (21 ears) with moderate to severe sensorineural hearing loss (SNHL) participated in this study. The compression methods of hearing aids were adjusted to implement the base increase at low level (BILL), treble increase at low level (TILL), and Multichannel compression (MCC), and the compression ratio in these cases was $2: 1$. After varying the compression methods of the hearing aid according to the frequency band, the SRS, clarity of speech sounds, perception of changes in the background noise, and overall preference for the sound quality were investigated in a quiet, $6 \mathrm{~dB}$ and $0 \mathrm{~dB}$ signal-to-noise ratios (SNRs). Results: For SRS, scores of MCC were higher than those of either BILL or TILL in the case of a quiet and $6 \mathrm{~dB}$ SNR, and no difference in SRS was found between BILL and TILL. In the subjective evaluation, MCC and BILL were found to have higher scores than TILL, while there was no difference between BILL and MCC. Conclusion: This study confirmed that for Korean with SNHL, it was effective in terms of the SRS or clarity of speech sounds to implement compression for all frequencies. However, it is considered necessary to conduct further research upon the effective compression ratio and compression threshold according to the hearing threshold level for adequate electroacoustic adjustment of hearing aids for Korean with hearing impairment.
\end{abstract}

Key Words: Bass increase at low level, Treble increases at low level, Multi-channel compression, Compression ratio, Signal-to-noise ratio, Non-linear hearing aid.

Received: August 12, 2016 / Revised: September 21, 2016 / Accepted: September 30, 2016

Correspondence: Kyoungwon Lee, Department of Audiology, Hallym University of Graduate Studies, 405 Yeoksam-ro, Gangnam-gu, Seoul 06198, Korea Tel: +82-2-2051-4951 / Fax: +82-2-3453-7833 / E-mail: hearing1004@naver.com

\section{INTRODUCTION}

현재 보청기의 기술은 디지털 기술의 접목으로 난청인의 의 사소통 능력의 개선에 많은 도움을 주고 있다. 최근까지의 보청 기의 기술을 간략히 살펴보면 채널 수의 증가, 음향피드백, 폐 쇄효과, 잡음 등의 효과적인 제어, 난청인이 듣기 힘든 고주파 수 대역의 정보를 잔존청력이 남아 있는 주파수 대역에서 듣게 하는 주파수하강(frequency lowering), 양측에 착용한 보청기 의 정보를 서로 교환하여 신호를 처리하는 양이통신 등이 있다
(Bohnert et al., 2010; Glista et al., 2009; Lee, 2014). 그러나 보 청기의 기술이 발전했음에도 불구하고 내이의 손상으로 인해 역동범위가 감소한 감각신경성난청인에게 보청기를 적합할 경 우에는 상기의 보청기 기술과 아울러 비선형의 증폭 특성 및 조절 방식에 대한 이해가 필요하다.

비선형 보청기의 전기음향적 조절 파라미터는 이득, 최대출력 (maximum power output) 또는 OSPL90 (output sound pressure level for $90 \mathrm{~dB}$ input sound pressure level), 압축비율 (compression ratio, CR), 압축역치(compression threshold, 
$\mathrm{CT}$ ), 압축시간(attack time, AT), 해제시간(release time, RT) 등이 있다. 여기에서 압축과 관련된 $\mathrm{CR}$ 과 $\mathrm{CT}$ 는 감각신경성난 청인의 좁은 역동범위와 관련이 있다. 일반적으로 $\mathrm{CR}$ 은 청력역 치레벨의 증가로 인해 역동범위가 좁을수록 $\mathrm{CR}$ 은 높아진다. 그 러나 $3: 1$ 이상의 높은 $\mathrm{CR}$ 은 단어인지도(word recognition score, WRS)나 소음 하에서의 음질에 나쁜 영향을 줄 수 있다(Boike \& Souza, 2000; Hornsbya \& Ricketts, 2001; Souza \& Kitch, 2001). 그리고 CT는 낮을수록 청력역치레벨의 개선으로 인하 여 작은 소리 또는 어음청취력이 증가한다. 그러나 중도에서 심 도의 감각신경성 난청인은 일반 대화음수준인 $65 \mathrm{~dB} \mathrm{SPL}$ 또는 그 이상의 CT를 선호한다는 보고가 있었다(Barker \& Dillon, 1999; Choi \& Lee, 2011). AT와 RT는 빠르게 또는 느리게 조절 하여 주변의 다양한 소리와 어음의 주파수 및 강도적인 요소에 변화를 주어 감각신경성난청인의 어음 인지에 도움을 줄 수 있 다. 즉, AT와 RT를 빠르게 설정하여 자모음비(consonant-tovowel ratio)를 개선할 수 있으며(Jenstad \& Souza, 2005; Van Toor \& Verschuure, 2002), 해제시간을 느리게 설정하여 신호 대잡음비(signal-to-noise ratio, SNR)를 개선할 수 있다(Gatehouse et al., 2006; Hansen, 2002).

비선형 보청기는 저음역압축(bass increase at low levels, BILL)과 고음역압축(treble increases at low levels, TILL) 방 식으로 간단하게 분류할 수 있다. 각각의 압축 방식에 따른 특 징을 간단히 살펴보면 보청기로 유입되는 음압이 감소할 때 BILL은 저주파수 대역의 이득이 증가하는 것으로 SNR이 개 선되어 소음 하에서 어음의 인지력을 높여줄 수 있다. TILL은 고주파수 대역의 이득이 증가하는 것으로 자모음비의 개선에 효과적이다. 그리고 후에 등장한 다채널압축(multi-channel compression, $\mathrm{MCC}$ ) 방식은 BILL과 TILL의 기능을 함께 수 행할 수 있는 장점을 가지고 있어서 다양한 청취 환경에서 난청 인의 어음 인지에 많은 도움을 줄 수 있다(Lee \& Lee, 2005).

여러 연구에서 한국어는 어음스펙트럼(Lee et al., 2008; Von Hapsburg \& Bahng, 2006) 및 대역중요기능(band-importance function) (Jin et al., 2015; Lee \& Kim, 2012)에 있어서 영어와 차이가 있음을 보고하였다. 그럼에도 불구하고 최근까지 BILL, TILL, MCC 등 증폭 방식에 따른 한국어음의 인지도, 선호도 등에 대한 연구가 부족하다. 이에 본 연구에서는 다채널 보청기 의 증폭 방식을 BILL, TILL 그리고 $\mathrm{MCC}$ 로 조절하고 배경잡 음의 $\mathrm{SNR}$ 을 다양하게 설정하여 감각신경성난청인에게 들려주 었을 때 문장인지도(sentence recognition score, SRS), 문장의 명료성(clarity), 배경잡음(background noise)의 변화에 대한 느 낌, 전체적인 선호도(overall preferences)의 차이를 알아보고 자 하였다. 본 연구의 결과를 통하여 한국어를 사용하는 난청 인에 대한 보청기 적합 시 주파수반응곡선 등 전기음향적 조절
파라미터의 설정에 도움을 주고자 하였다.

\section{MATERIALS AND METHODS}

\section{연구 대상}

본 연구에서는 육안검사(otoscopy) 시 외이도 및 고막의 형태 가 정상 소견을 보였으며, 중이염 등의 이과적 질환과 약물 복 용, 소음 노출, 두부 외상 또는 신경학적 질환 등의 과거력이 없 는 감각신경성난청인을 대상으로 하였다. 대상자의 연령은 평 균 73.3세(범위; 55 84세)로 보청기의 착용 기간은 평균 22.8개 월(범위; 1 103개월)이었다. 대상자의 순음역치평균(pure tone average)의 평균은 $55.5 \mathrm{~dB} \mathrm{HL}$ (범위; 43.3 73.3 dB HL), 단어 인지도의 평균은 58.0\%(범위; 32 75\%)였다. 그리고 대상자가 착용한 보청기는 고막보청기(completely-in-the-canal)가 4개, 외이도보청기(in-the-canal)가 8개, 개방보청기(receiver-inthe-canal)가 9개였으며, 채널의 수는 4 9 채널이었다. 그리고 $500 \mathrm{~Hz}$ 와 4,000 Hz의 AT는 5 10 msec와 5 5 msec, RT는 65 85 msec와 46 72 msec였다. 대상자의 성별, 나이, 검사 귀, 착용 기간은 Table 1, 검사 귀의 주파수별 순음 청력역치레벨,

Table 1. Informations (gender, age, test ear, used period of hearing aid) of subjects in this study

\begin{tabular}{|c|c|c|c|c|}
\hline Subjects & Gender & Age & Test ear & $\begin{array}{c}\text { Used period } \\
\text { (month) }\end{array}$ \\
\hline S1 & $\mathrm{M}$ & 82 & RT & 30 \\
\hline S2 & $\mathrm{F}$ & 73 & LT & 109 \\
\hline S3 & M & 72 & RT & 33 \\
\hline S4 & M & 75 & RT & 11 \\
\hline S5 & M & 75 & $\mathrm{LT}$ & 11 \\
\hline S6 & M & 78 & $\mathrm{LT}$ & 6 \\
\hline S7 & M & 77 & $\mathrm{LT}$ & 8 \\
\hline S8 & M & 77 & RT & 8 \\
\hline S9 & M & 72 & $\mathrm{LT}$ & 1 \\
\hline S10 & M & 67 & $\mathrm{LT}$ & 11 \\
\hline S11 & $\mathrm{F}$ & 78 & RT & 21 \\
\hline S12 & $\mathrm{F}$ & 82 & $\mathrm{LT}$ & 23 \\
\hline S13 & M & 73 & $\mathrm{LT}$ & 39 \\
\hline S14 & $\mathrm{F}$ & 84 & LT & 15 \\
\hline S15 & $\mathrm{F}$ & 66 & LT & 23 \\
\hline S16 & M & 68 & LT & 36 \\
\hline S17 & M & 55 & LT & 18 \\
\hline S18 & M & 55 & LT & 46 \\
\hline S19 & $\mathrm{F}$ & 74 & LT & 25 \\
\hline S20 & M & 80 & RT & 2 \\
\hline S21 & M & 76 & LT & 3 \\
\hline Mean & & 73.3 & & 22.8 \\
\hline SD & & 7.7 & & 23.5 \\
\hline
\end{tabular}

SD: standard deviation 
Table 2. Hearing threshold levels, MCLs, and WRSs of test ear for 21 subjects

\begin{tabular}{|c|c|c|c|c|c|c|c|c|}
\hline \multirow{2}{*}{ Subjects } & \multicolumn{6}{|c|}{ Hearing threshold level (dB HL) } & \multirow{2}{*}{ MCL (dB HL) } & \multirow{2}{*}{ WRS (\%) } \\
\hline & $250 \mathrm{~Hz}$ & $500 \mathrm{~Hz}$ & $1,000 \mathrm{~Hz}$ & $2,000 \mathrm{~Hz}$ & $4,000 \mathrm{~Hz}$ & $8,000 \mathrm{~Hz}$ & & \\
\hline S1 & 30 & 40 & 55 & 65 & 70 & 70 & 90 & 72 \\
\hline S2 & 40 & 65 & 55 & 55 & 55 & 80 & 80 & 66 \\
\hline S3 & 60 & 70 & 75 & 75 & 80 & 85 & 95 & 56 \\
\hline S4 & 30 & 45 & 50 & 55 & 75 & 75 & 90 & 64 \\
\hline S5 & 35 & 40 & 50 & 75 & 75 & 70 & 90 & 56 \\
\hline S6 & 50 & 60 & 65 & 60 & 80 & 90 & 90 & 64 \\
\hline S7 & 50 & 55 & 55 & 55 & 45 & 55 & 90 & 52 \\
\hline S8 & 35 & 45 & 60 & 70 & 75 & 85 & 90 & 40 \\
\hline S9 & 35 & 40 & 45 & 50 & 65 & 70 & 90 & 50 \\
\hline S10 & 40 & 35 & 50 & 65 & 90 & 100 & 85 & 40 \\
\hline S11 & 40 & 45 & 50 & 60 & 70 & 75 & 85 & 32 \\
\hline S12 & 55 & 60 & 65 & 60 & 65 & 75 & 95 & 60 \\
\hline S13 & 30 & 50 & 50 & 60 & 70 & 80 & 85 & 48 \\
\hline S14 & 35 & 40 & 55 & 70 & 60 & 65 & 90 & 72 \\
\hline S15 & 35 & 45 & 50 & 50 & 60 & 65 & 90 & 56 \\
\hline S16 & 65 & 70 & 65 & 65 & 75 & 70 & 95 & 67 \\
\hline S17 & 50 & 60 & 65 & 70 & 65 & 85 & 95 & 56 \\
\hline S18 & 50 & 75 & 65 & 60 & 65 & 70 & 95 & 60 \\
\hline S19 & 40 & 45 & 50 & 50 & 60 & 65 & 60 & 75 \\
\hline S20 & 30 & 35 & 35 & 60 & 75 & 75 & 55 & 72 \\
\hline S21 & 45 & 45 & 35 & 55 & 55 & 55 & 65 & 68 \\
\hline Mean & 41.9 & 50.7 & 54.5 & 61.2 & 68.1 & 74.3 & 85.7 & 58.0 \\
\hline SD & 10.3 & 11.9 & 9.5 & 7.7 & 10.3 & 11.0 & 11.5 & 11.8 \\
\hline
\end{tabular}

MCL: most comfortable level, WRS: word recognition score, SD: standard deviation

Table 3. Type, numbers of channel, AT and RT of subjects' hearing aids

\begin{tabular}{|c|c|c|c|c|c|c|}
\hline \multirow{2}{*}{ Subjects } & \multirow{2}{*}{ Hearing aid type } & \multirow{2}{*}{$\mathrm{N}$ of channel } & \multicolumn{2}{|c|}{ AT (msec) } & \multicolumn{2}{|c|}{ RT (msec) } \\
\hline & & & $500 \mathrm{~Hz}$ & $4,000 \mathrm{~Hz}$ & $500 \mathrm{~Hz}$ & $4,000 \mathrm{~Hz}$ \\
\hline S1 & ITC & 7 & 5 & 5 & 85 & 63 \\
\hline S2 & ITC & 4 & 5 & 5 & 85 & 63 \\
\hline S3 & ITC & 4 & 10 & 6 & 70 & 62 \\
\hline S4 & RIC & 7 & 5 & 5 & 60 & 46 \\
\hline S5 & RIC & 7 & 10 & 6 & 70 & 62 \\
\hline S6 & RIC & 7 & 5 & 5 & 85 & 63 \\
\hline S7 & CIC & 4 & 5 & 5 & 60 & 46 \\
\hline S8 & $\mathrm{CIC}$ & 4 & 10 & 6 & 70 & 61 \\
\hline S9 & RIC & 7 & 10 & 6 & 70 & 61 \\
\hline S10 & RIC & 9 & 10 & 6 & 80 & 66 \\
\hline S11 & RIC & 9 & 10 & 6 & 70 & 62 \\
\hline S12 & ITC & 4 & 10 & 6 & 70 & 62 \\
\hline S13 & RIC & 7 & 5 & 5 & 60 & 46 \\
\hline S14 & RIC & 7 & 10 & 6 & 70 & 62 \\
\hline S15 & ITC & 4 & 10 & 6 & 70 & 62 \\
\hline S16 & ITC & 6 & 5 & 5 & 85 & 63 \\
\hline S17 & RIC & 7 & 5 & 5 & 60 & 46 \\
\hline $\mathrm{S} 18$ & ITC & 6 & 10 & 6 & 70 & 62 \\
\hline S19 & CIC & 4 & 10 & 5 & 85 & 72 \\
\hline S20 & ITC & 4 & 10 & 5 & 65 & 52 \\
\hline S21 & CIC & 4 & 5 & 5 & 85 & 63 \\
\hline
\end{tabular}

N: number, AT: attack time, RT: release time, CIC: completely-in-the-canal, ITC: in-the-canal, RIC: receiver-in-the-canal 


\begin{tabular}{|c|c|c|c|c|c|c|c|c|c|c|}
\hline & \multirow[t]{2}{*}{ Clarity } & \multicolumn{2}{|l|}{$\begin{array}{c}\text { Very } \\
\text { unclear }\end{array}$} & \multicolumn{2}{|l|}{$\begin{array}{l}\text { Rather } \\
\text { unclear }\end{array}$} & \multicolumn{2}{|l|}{ Midway } & \multicolumn{2}{|l|}{$\begin{array}{c}\text { Rather } \\
\text { clear }\end{array}$} & $\begin{array}{l}\text { Very } \\
\text { clear }\end{array}$ \\
\hline & & 1 & 2 & 3 & 4 & 5 & 6 & 7 & 8 & 9 \\
\hline & Backoround noise & $\begin{array}{l}\text { Very } \\
\text { noisy }\end{array}$ & & $\begin{array}{c}\text { Rather } \\
\text { noisy }\end{array}$ & & Midway & & $\begin{array}{l}\text { Rather } \\
\text { quiet }\end{array}$ & & $\begin{array}{l}\text { Very } \\
\text { quiet }\end{array}$ \\
\hline & & 1 & 2 & 3 & 4 & 5 & 6 & 7 & 8 & 9 \\
\hline & Overall preference & Very bad & & Rather bad & & Midway & 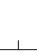 & Rather good & $\perp$ & Very good \\
\hline $\begin{array}{l}\text { Figure } 1 . \text { A sample of the response form } \\
\text { used for rating procedure. }\end{array}$ & & 1 & 2 & 3 & 4 & 5 & 6 & 7 & 8 & 9 \\
\hline
\end{tabular}

쾌적수준 그리고 WRS는 Table 2, 대상자가 착용한 보청기의 형태, 채널 수 그리고 AT, RT는 Table 3에 나타내었다. 그리고 본 연구를 위해 한림국제대학원대학교의 생명윤리위원회의 심 사를 필하였다(심의번호: HUGSAUD583261).

\section{연구 장비}

외이도의 육안검사는 이경을 사용하였고, 보청기 착용 전 기 도 및 골도 순음청력역치, WRS, 쾌적수준은 AURICAL (GN Otometrics, Copenhagen, Denmark)과 TDH-39 헤드폰을 사 용하였다. 보청기 착용 후 문장과 잡음은 방음실에 설치한 외부 스피커(4 Ohms)를 통하여 제시하였다. 압축 방식의 효과를 측 정하기 위한 SRS는 노트북(Samsung, Seoul, Korea)에 wave 파 일로 저장한 한국산업표준 문장(KS-SL-A) (Jang et al., 2008; KS I ISO 8253-3, 2009)을 사용하였다. 보청기의 전기음향적 특성은 AURICAL (GN Otometrics)을 이용하여 분석하였다. 그리고 보청기 착용 후 제시한 문장의 명료성, 배경잡음의 변 화, 전체적인 선호도 평가하기 위한 설문지는 1 에서 9단계로 구 분하여 평가하였다(Figure 1).

\section{연구 절차}

\section{압축 방식의 조절}

압축 방식의 조절은 첫째, 순음 기도 및 골도 청력을 보청기 적합 소프트웨어에 입력하고 제조사의 보청기적합공식(audiogram+)을 선택한 후 자동적합(auto fit)을 사용하여 보청기의 전기음향적 파라미터를 조절하였다. 이때 주파수 반응에 의한 음질 및 어음인지도를 평가하기 위해 방향성, 소음감소, 확장기 능을 비활성화하였다. 둘째, 보통 크기의 목소리를 들려 준 후 난청인의 주관적인 판단을 기준으로 음량은 적당하고, 음질은 대상자의 주관적인 판단을 근거로 하여 최대한 자연스럽게 조 절하였다. 셋째, Table 4와 같이 BILL은 $500 \mathrm{~Hz}$ 대역, TILL은 $3,000 \mathrm{~Hz}$ 대역 그리고 $\mathrm{MCC}$ 는 전 주파수 대역의 $\mathrm{CR}$ 을 $2: 1$ 로 조절하였으며, CT는 $50 \mathrm{~dB} \mathrm{SPL}$ 이하로 설정하였다.
Table 4. Compression ratios of three different compression types (BILL, TILL, MCC) in $500 \mathrm{~Hz}$ and $4,000 \mathrm{~Hz}$

\begin{tabular}{rccc}
\hline & BILL & TILL & MCC \\
\hline $500 \mathrm{~Hz}$ & $2: 1$ & $1: 1$ & $2: 1$ \\
$4,000 \mathrm{~Hz}$ & $1: 1$ & $2: 1$ & $2: 1$ \\
\hline
\end{tabular}

BILL: bass increase at low level, TILL: treble increases at low level, MCC: multi-channel compression

\section{$\mathrm{SRS}$ 의 측정}

SRS의 평가를 위해 우선 한국산업표준 문장 파일을 컴퓨터 에 저장한 후 청력검사와 연결하였다. 그리고 $1,000 \mathrm{~Hz}$ 의 보정 음을 이용하여 음량계(volume unit meter) 상에서 ' 0 '을 가리키 도록 컴퓨터와 청력검사기의 볼륨을 조절하였다. 문장과 잡음 은 피검자 정면의 $1 \mathrm{~m}$ 거리에 있는 2 개의 스피커에서 각각 그 리고 동시에 제시하였다. SRS 평가를 위해 모든 상황에서 서로 다른 한 개의 목록을 사용하였다. 문장의 강도는 $50 \mathrm{~dB} \mathrm{HL}$ 로 고정하였으며, 잡음은 조용한 상황, $44 \mathrm{~dB} \mathrm{HL}$ (6 dB SNR), 50 $\mathrm{dB}$ HL (0 dB SNR)로 제시하였다.

\section{선호도의 평가}

제시한 문장의 선호도는 Nueman et al.(1998)의 선호도 연 을 참고하여 연구를 참고하여 압축 방식을 BILL, TILL, MCC 방식으로 조절한 후 조용한 상황, $6,0 \mathrm{~dB}$ SNR에서 SRS를 측 정한 다음 각각의 압축 방식에서 문장의 명료성, 배경잡음의 변화, 전체적인 선호도에 대한 주관적 느낌을 대상자에게 질문 하여 답하게 하였다.

\section{통계 분석}

조용한 상황, 6, $0 \mathrm{~dB}$ SNR에서 BILL, TILL, MCC의 압축 방식에 따른 SRS의 차이는 Two-way mixed ANOVA로 분석 한 후 Bonferroni 사후분석을 통하여 검정하였다. 선호도는 비 모수검정 Friedman test를 통하여 분석한 후 Wilcoxon 사후분 석을 통하여 검정하였다. 자료 분석은 Window용 SPSS version 17.0 (SPSS Inc., Chicago, IL, USA)을 사용하여 유의수 준 0.01 혹은 0.05 미만에서 하였다. 


\section{RESULTS}

\section{주파수 대역별 압축 방식에 따른 문장인지도}

BILL, TILL, MCC의 SRS는 조용한 상황에서 73.2, 69.4, $80.1 \%, 6 \mathrm{~dB}$ SNR에서 61.9, 53.6, 71.3\% 그리고 $0 \mathrm{~dB}$ SNR에서 $47.4,44.9,54.6 \%$ 로 각각 나타났다(Figure 2). Table 5에서 조용 한 상황, $6 \mathrm{~dB}, 0 \mathrm{~dB}$ SNR의 청취 상황과 BILL, TILL, MCC의 압축 방식에 따른 SRS에 대한 Two-way mixed ANOVA의 분 석 결과 $\mathrm{SRS}$ 는 청취 상황 $[\mathrm{F}(2,40)=66.74, p<0.001]$ 과 압축 방식 $[\mathrm{F}(2,40)=13.52, p<0.001]$ 에 따른 차이가 나타났다. 그러 나 SNR과 압축 방식 간의 상호작용은 나타나지 않았다 $[\mathrm{F}(4,80)$ $=1.23, p>0.05]$. Bonferroni 사후분석 결과 EILL의 SRS는 $\operatorname{BILL}(p<0.01)$ 과 $\operatorname{TILL}(p<0.001)$ 에 비해 높게 나타났으나, BILL과 TILL 간에는 차이가 나타나지 않았다 $(p>0.005)$.

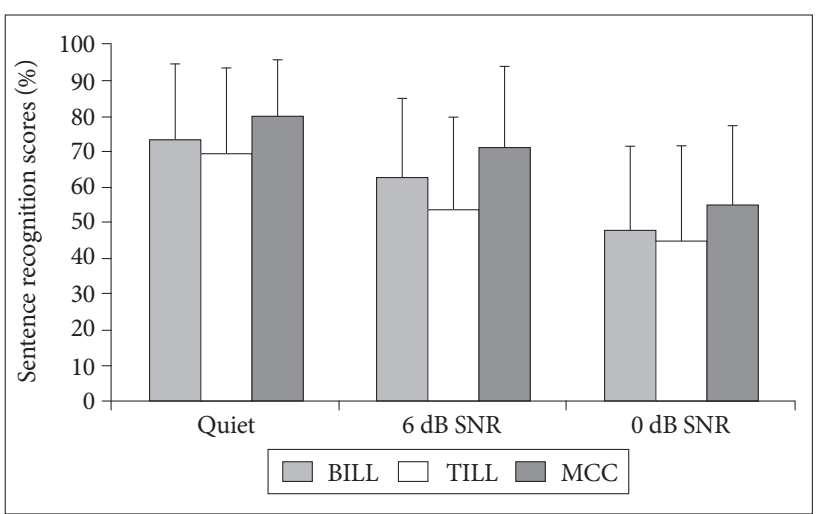

Figure 2. Means of the sentence recognition scores for three compression types (BILL, TILL, MCC) in each listening conditions (quiet, $6 \mathrm{~dB}$ SNR, $0 \mathrm{~dB}$ SNR). BILL: bass increase at low level, TILL: treble increases at low level, MCC: multi-channel compression, SNR: signal-to-noise ratios.

Table 5. Results of two-way mixed ANOVA for sentence recognition performance in each listening situation (quiet, $6 \mathrm{~dB}$ and $0 \mathrm{~dB}$ SNR) according to each compression type (BILL, TILL, MCC)

\begin{tabular}{lccc}
\hline & $\mathrm{F}$ & $\mathrm{df}$ & $p$ \\
\hline Main effects & & & \\
Listening situation (quiet, 6 dB, 0 dB) & 66.74 & 2,40 & 0.000 \\
Compression type (BILL, TILL, MCC) & 13.52 & 2,40 & 0.000
\end{tabular}

Interaction

Listening situation $*$ Compression type $\quad 1.23 \quad 2,80 \quad 0.304$

BILL: bass increase at low level, TILL: treble increases at low level, MCC: multi-channel compression, SNR: signal-to-noise ratios

\section{주파수 대역별 압축 방식에 따른 선호도}

문장의 명료성에 대한 선호도 평균은 BILL 6.2점, TILL 5.31 점, MCC 6.6점으로 나타났다(Figure 3). 압축 방식에 따른 문 장의 명료성의 Friedman 검정 결과(Table 6) 중위수는 BILL 이 7, TILL이 6, MCC가 7이고 주파수대역별 CR에 따른 순위 합은 $\mathrm{MCC}$ 가 2.36, BILL이 2.14, TILL이 1.5로 $\mathrm{MCC}$ 의 중위수 가 가장 크고 TILL이 가장 작게 나타났다 $(p<0.05)$. Wilcoxon 검정결과 MCC와 BILL은 TILL에 비해서 문장의 명료성이 더 높게 나타났으나 $(p<0.01) \mathrm{MCC}$ 와 $\operatorname{BILL}$ 간의 차이는 나타나 지 않았다. 그리고 BILL, TILL MCC의 압축 방식에서 배경소 음 변화에 대한 느낌은 4.17점, 3.75점, 3.98점 그리고 음질의 선 호도는 6.10점, 5.76점, 36.32점으로 Friedman 검정 결과 압축 방식에 따른 차이는 나타나지 않았다 $(p>0.05)$.

\section{DISCUSSIONS}

본 연구에서는 압축 방식을 BILL, TILL, MCC로 변경하였 을 때의 SRS와 음질에 대한 선호도를 조용한 상황, $6 \mathrm{~dB}$ 및 0 $\mathrm{dB}$ SNR에서 감각신경성난청인을 대상으로 알아보았다.

본 연구의 결과에서 $\mathrm{MCC}$ 의 SRS가 BILL, TILL에 비해서 높게 나타났다 $(p<0.05)$. Palat et al.(2012)의 연구에서는 정점 절단(peak clipping), 광역동범위압축(wide dynamic range compression), 압축제한(compression limiting), 저주파수 대역 의 $\mathrm{CR}$ 이 $3: 1$ 인 BILL, 고주파수 대역의 CR이 $3: 1$ 인 TILL에서

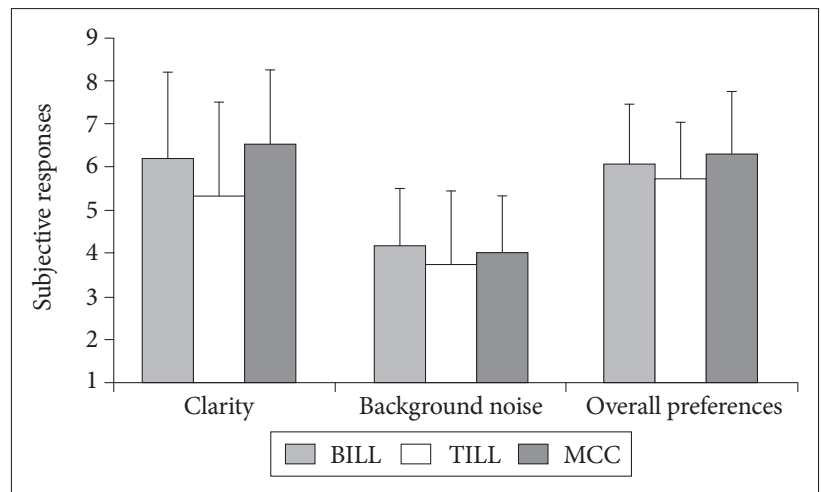

Figure 3. Mean scores of clarity, background and overall preference in each compression types (BILL, TILL, MCC). BILL: bass increase at low level, TILL: treble increases at low level, MCC: multi-channel compression.

Table 6. Descriptive statistics on the subjective responses for clarity in each compression types (BILL, TILL, MCC)

\begin{tabular}{|c|c|c|c|c|c|c|c|}
\hline & \multirow{2}{*}{ Mean } & \multirow{2}{*}{$\mathrm{SD}$} & \multirow{2}{*}{ Minimum } & \multirow{2}{*}{ Maximum } & \multicolumn{3}{|c|}{ 50th percentile } \\
\hline & & & & & 25 & 50 (median) & 75 \\
\hline$\overline{\text { BILL }}$ & 6.19 & 2.13 & 2 & 8 & 6 & 7 & 8 \\
\hline TILL & 5.31 & 2.37 & 1 & 8 & 3 & 6 & 7 \\
\hline MCC & 6.56 & 1.82 & 2 & 9 & 6 & 7 & 8 \\
\hline
\end{tabular}

BILL: bass increase at low level, TILL: treble increases at low level, MCC: multi-channel compression, SD: standard deviation 
터키어의 WRS를 알아보았는데 $6 \mathrm{~dB}, 0 \mathrm{~dB}$ SNR에서 TILL이 정점절단, BILL, 광역동범위압축 방식보다 높게 나타났다고 보 고하여 본 연구와 차이를 나타냈다. 그 원인을 살펴보면 BILL 은 SNR을, TILL은 자모음비를 개선하는 데 효과적인데 MCC 는 SNR과 자모음비를 동시에 개선할 수 있기 때문에 조용한 상황은 물론 잡음 하에서도 $\mathrm{MCC}$ 의 $\mathrm{SRS}$ 가 높게 나타난 것으 로 보인다. 또한 Palat et al.(2012)은 비선형 증폭 방식의 경우 높은 $\mathrm{CR}$ 을 사용하였고, $\mathrm{AT}, \mathrm{RT}$ 를 고려하지 않았으며, 제시음 으로 단음절어를 사용하였는데 이는 다양한 상황에서 증폭 방 식에 따른 어음인지의 효과를 알아보기에는 불충분한 방법으 로 보인다.

본 연구에서 대상자가 착용한 보청기에서 $4,000 \mathrm{~Hz}$ 의 AT는 5 6 msec, RT는 46 72 msec로 비교적 빠른 AT, RT를 사용하 였다. Van Toor \& Verschuure(2002)는 AT, RT를 빠르게 설정 하여 자모음비를 개선하여 어음의 인지도를 높일 수 있으며, Gatehouse et al.(2006)과 Hansen(2002)은 해제시간을 느리게 설정하여 SNR을 개선할 수 있다고 하였다. 본 연구에서의 SRS 는 자음이 주로 분포하는 고주파수 대역을 압축한 TILL과 어음 잡음의 에너지가 주로 분포하는 저주파수 대역을 압축한 BILL 간에 차이가 나타나지 않았다 $(p>0.05)$. 이는 BILL의 경우는 자모음비의 개선이, TILL의 경우는 SNR의 개선이 충분하지 않 았기 때문으로 보인다.

본 연구에서는 BILL, TILL, MCC의 CR을 $2: 1$ 로 고정하고 문장을 들려준 후 문장을 들려주었을 때 문장의 명료성에 있어 서 MCC는 TILL에 비해서 높게 나타났으나 $(p<0.05)$ BILL과 는 차이가 나타나지 않았다 $(p>0.05)$. 그 이유로 어음스펙트럼 은 $300 \mathrm{~Hz}$ 내외의 저주파수에서 $4,000 \mathrm{~Hz}$ 내외의 고주파수까지 폭 넓게 분포하는데(Lee et al., 2008) MCC의 경우 자모음비와 $\mathrm{SNR}$ 을 동시에 개선할 수 있으며, 상향차폐(upward spread of masking) 또한 방지할 수 있기 때문이다(Danaher \& Pickett, 1975; Lee \& Lee, 2005).

본 연구에서는 보청기의 압축 방식을 조절한 직후에 즉시 $\mathrm{SRS}$ 와 주관적인 평가를 실시하여 순응 기간, 즉 신경가소성 (Azari \& Seitz, 2000)을 고려하지 않았으며, 피검자의 평균 연 령이 73.3세로 높은 것은 본 연구의 한계점으로 남는다. 그리고 Byrne et al.(2001)의 연구에서 NAL-NL1을 다른 보청기적합공 식의 특성과 절차를 비교할 때 청력의 정도와 형태를 고려하였 듯이 압축 방식에 따른 한국어 SRS, 선호도 등에 대한 향후의 연구에서도 이러한 요소를 고려할 필요가 있다.

본 연구에서 한국어를 사용하는 감각신경성난청인은 저음역 또는 고음역 압축보다는 다채널압축 방식이 다양한 상황에서의 $\mathrm{SRS}$ 와 문장의 명료성에 있어서 효과적임을 확인하였다. 그러 나 한국 난청인에 대한 효과적인 비선형 보청기의 전기음향적
조절을 위해서는 청력역치레벨에 따른 최적의 $\mathrm{CR}$ 과 $\mathrm{CT}$, AT와 $\mathrm{RT}$ 그리고 이에 따른 어음인지 능력의 변화와 음질에 대한 선 호도 등에 대한 연구가 추가적으로 필요할 것이다.

중심 단어 : 저음역압축·고음역압축·다채널압축·압축비율· 신호대잡음비·비선형 보청기.

\section{REFERENCES}

Azari, N. P. \& Seitz, R. J. (2000). Brain plasticity and recovery from stroke: What has changed in the brain of a stroke patient who recovers the ability to move a once-disabled limb? American Scientist, 88(5), 426431.

Barker, C. \& Dillon, H. (1999). Client preferences for compression threshold in single-channel wide dynamic range compression hearing aids. Ear and Hearing, 20(2), 127-139.

Bohnert, A., Nyffeler, M., \& Keilmann, A. (2010). Advantages of a nonlinear frequency compression algorithm in noise. European Archives of Oto-Rhino-Laryngology, 267(7), 1045-1053.

Boike, K. T. \& Souza, P. E. (2000). Effect of compression ratio on speech recognition and speech-quality ratings with wide dynamic range compression amplification. Journal of Speech, Language, and Hearing Research, 43(2), 456-468.

Byrne, D., Dillon, H., Ching, T., Katsch, R., \& Keidser, G. (2001). NAL-NL1 procedure for fitting nonlinear hearing aids: Characteristics and comparisons with other procedures. Journal of the American Academy of Audiology, 12(1), 37-51.

Choi, M. J. \& Lee, K.W. (2011). Case reports of improving sound quality by compression threshold control. Audiology, 7(1), 100-105.

Danaher, E. M. \& Pickett, J. M. (1975). Some masking effects produced by low-frequency vowel formants in persons with sensorineural hearing loss. Journal of Speech, Language, and Hearing Research, 18(2), 261-271.

Gatehouse, S., Naylor, G., \& Elberling, C. (2006). Linear and nonlinear hearing aid fittings--2. Patterns of candidature. International Journal of Audiology, 45(3), 153-171.

Glista, D., Scollie, S., Bagatto, M., Seewald, R., Parsa, V., \& Johnson, A. (2009). Evaluation of nonlinear frequency compression: Clinical outcomes. International Journal of Audiology, 48(9), 632-644.

Hansen, M. (2002). Effects of multi-channel compression time constants on subjectively perceived sound quality and speech intelligibility. Ear and Hearing, 23(4), 369-380.

Jang, H. S., Lee, J. H., Lim, D. H., Lee, K. W., Jeon, A. R., \& Jung, E. J. (2008). Development of Korean standard sentence lists for sentence recognition tests. Audiology, 4(2), 161-177.

Jenstad, L. M. \& Souza, P. E. (2005). Quantifying the effect of compression hearing aid release time on speech acoustics and intelligibility. Journal of Speech, Language, and Hearing Research, 48(3), 651-667.

Jin, I. K., Kates, J. M., Lee, K., \& Arehart, K. H. (2015). Derivations of the band-importance function: A cross-procedure comparison. The Journal of the Acoustical Society of America, 138(2), 938-941.

Korean Agency for Technology and Standards (2009). Acoustics-Audiometric test methods-Part 3: Speech audiometry. KSI ISO 8253-3. Seoul: Korean Agency for Technology and Standards.

Lee, J. H. \& Lee, K. W. (2005). Hearing aid Evaluation. (pp.142-148). Seoul: Hakjisa.

Lee, K. W. (2014). Changes of dynamic range, signal-to-noise ratio, and consonant-to-vowel ratio by electroacoustic adjustment and fitting in non-linear hearing aids. Audiology, 10(3), 190-197.

Lee, K. Y. \& Kim, J. S. (2012). The study of frequency importance function of the Korean monosyllabic words. Audiology, 8, 24-33.

Lee, K. W., Lee, J. H., \& Lee, J. (2008). Suggestions of multi-talker babble noise using Korean speech sound. Audiology, 4(1), 24-27. 
Neuman, A. C., Bakke, M. H., Mackersie, C., Hellman, S., \& Levitt, H. (1998). The effect of compression ratio and release time on the categorical rating of sound quality. The Journal of the Acoustical Society of America, 103(5), 2273.

Polat, Z., Atas, A., \& Sennaroglu, G. (2012). Effects of multi-channel compression on speech intelligibility at the patients with loudness-recruitment. Journal of International Advanced Otology, 8(1), 94-102.

Souza, P. E. \& Kitch, V. (2001). The contribution of amplitude envelope cues to sentence identification in young and aged listeners. Ear and Hearing, 22(2), 112-119.

Van Toor, T. \& Verschuure, H. (2002). Effects of high-frequency emphasis and compression time constants on speech intelligibility in noise. International Journal of Audiology, 41(7), 379-394.

Von Hapsburg, D. \& Bahng, J. (2006). Acceptance of background noise levels in bilingual (Korean-English) listeners. Journal of the American Academy of Audiology, 17(9), 649-658. 